\title{
Cystic adventitial disease of the common femoral vein
}

\author{
Emma Howard, ${ }^{1}$ Ruth Benson, ${ }^{2}$ Christopher Day, ${ }^{3}$ Brian Gwynn ${ }^{2}$
}

${ }^{1}$ School of Medicine, Keele University, Keele, UK ${ }^{2}$ Department of Vascular Surgery, University Hospitals of North Midlands NHS Trust, Stoke-on-Trent, Staffordshire, UK ${ }^{3}$ Department of Radiology, University Hospitals of North Midlands NHS Trust, Stoke-onTrent, Staffordshire, UK

\section{Correspondence to}

Emma Howard,

emm.howard@btinternet.com

Accepted 25 April 2017

To cite: Howard E, Benson $R$, Day C, et al. BMJ Case Rep Published Online First: [please include Day Month Year]. doi:10.1136/bcr-2017219818

\section{SUMMARY}

We present the case of a 46-year-old commercial pilot with a history of unilateral leg swelling following a flight to Geneva. Although initial clinical examination suggested a deep vein thrombosis, the swelling only partially resolved with anticoagulation and further imaging suggested the presence of adventitial cystic disease (ACD). The patient underwent initial anticoagulation to allow any thrombus to be lysed, followed by excision of the ACD from the venous wall and venous reconstruction. Following the excision of the $A C D$, providing the patient remains asymptomatic and further imaging finds normal venous anatomy, we hope the patient will discontinue anticoagulation and return to flying.

\section{BACKGROUND}

Adventitial cystic disease (ACD) of the venous system is a rare condition, with less than 40 documented venous cases worldwide. Clinically, it is difficult to diagnose due to the frequent coexistence of a deep vein thrombosis (DVT), or comparable symptoms from a venous occlusion with no thrombosis evident.

A high index of suspicion is needed to diagnose ACD, and it should be considered as a differential for a patient presenting with unilateral leg swelling. Although this condition is more frequently seen in arteries, it has been recognised in the venous system. This condition is described in a young, fit airline pilot, and associated MRIs and operative pictures are included to illustrate this unusual but important pathology. For our patient, any condition or medication that could potentially affect his ability to fly an aircraft would prevent him from returning to work. Therefore, it was of upmost importance to ensure that the ACD was managed in a way that would minimise the risk of recurrence to allow him to return to work as soon as possible.

\section{CASE PRESENTATION}

A 46-year-old male airline pilot presented in June 2016 with mild pain and swelling of the right leg, shortly after a flight from the UK to Switzerland. Clinical examination suggested a DVT, but a CT venogram (CTV) obtained in Geneva immediately on arrival demonstrated a localised and only partially occluding DVT within the right common femoral vein (CFV). Subcutaneous heparin anticoagulation therapy was commenced together with a below knee external compression stocking and he was repatriated to the UK. He was advised to see a vascular surgeon on return to England and did so within 2 days of developing symptoms.

\section{INVESTIGATIONS}

Duplex ultrasound imaging was carried out together with review of the CTV from Geneva. Duplex demonstrated a hypoechoic cystic structure related to the right CFV without thrombus (figure 1). The initial CTV performed abroad demonstrated a patent right CFV with a cystic lesion within it and a small volume of thrombus just inferior to it (figure 2). These findings raised the suspicion of ACD of the right CFV. Treatment with low molecular weight heparin was switched to apixaban $5 \mathrm{mg}$ two times daily, which was prescribed for 3 months. It was expected that this would allow the thrombotic component to resolve completely. Potential further treatment was discussed at the local multidisciplinary vascular meetings, and an MR venogram was performed at 3 months that confirmed diagnosis of ACD with resolution of the thrombotic component seen previously (figure 3).

\section{TREATMENT}

After 3 months of anticoagulation and external compression, all symptoms had resolved. There was no leg swelling and the patient was active and fully mobile. He had not however been allowed to return to flying, until a definitive prognosis for his condition could be given. In view of the likelihood of further thrombosis occurring, long-term anticoagulation was discussed, and possible resection of the ACD was also contemplated.

In early October, $3 \frac{1}{2}$ months following initial presentation the pathology of the CFV was resected with a portion of the posterior vein wall. Access was gained by an anterior venotomy, which allowed the resection to be done from inside the vein (figures 4 and 5). The defect was repaired with a vein patch obtained from the adjacent long saphenous vein, and a similar patch of vein was also used to close the anterior venotomy, restoring normal venous anatomy (figure 5). This surgical approach was chosen as the ACD arose from a small segment of the CFV ( $<2 \mathrm{~cm}$ in length) and was only partially occluding the CFV. By using vein patches to close the defects from the anterior venotomy and from the area of excision of the ACD, it was hoped that the reconstructed CFV would not be narrowed and thus normal venous anatomy restored. Histology of the resected vein wall confirmed our clinical 


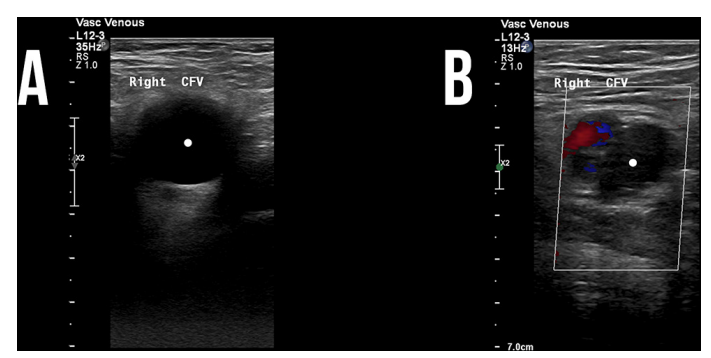

Figure 1 Ultrasound of the right common femoral vein (CFV) without (A) and with (B) colour Doppler demonstrates the anechoic cystic lesion with no colour flow in it (circle).

suspicions of ACD, with cystic degeneration and fibrous connective tissue around it (figure 6).

\section{OUTCOME AND FOLLOW-UP}

This patient was maintained on oral anticoagulants for 3 months, after which he was seen for a postoperative follow-up in clinic. He remained clinically asymptomatic, with no leg swelling. A follow-up duplex ultrasound to assess the patency of the CFV and for possible recurrence of ACD was conducted in March 2017. Duplex ultrasound demonstrated a patent CFV, with mild narrowing and some turbulent flow, but no recurrence of ACD. Consequently, oral anticoagulation treatment has been stopped. This was important for this patient as although the UK civil aviation authority are prepared to let air crew fly while taking oral anticoagulants providing they are causing no side effects, and there are no risks from the underlying condition, this patient is only able to fly as co-pilot if taking oral anticoagulation. If the follow-up ultrasound had shown an occluded CFV, anticoagulation would have been continued until a stable venous collateral drainage had formed, at which point anticoagulation would have had little long-term benefit for the patient and could therefore be discontinued.

\section{DISCUSSION}

ACD is the collection of mucin and polysaccharide-containing fluid within the adventitia of blood vessels. As the mucin and polysaccharide fluid accumulates and expands, the cyst compresses the structure it is located on, either an artery or vein. There are a number of hypotheses speculating the possible aetiology of arterial ACD. These include the 'developmental theory', where mesenchymal cells from joints are embryonically incorrectly located in blood vessels and go on to produce mucin later in life, and the 'repetitive trauma theory' where movement and injury from nearby joints cause the cystic degeneration of the adventitia. ${ }^{1}$

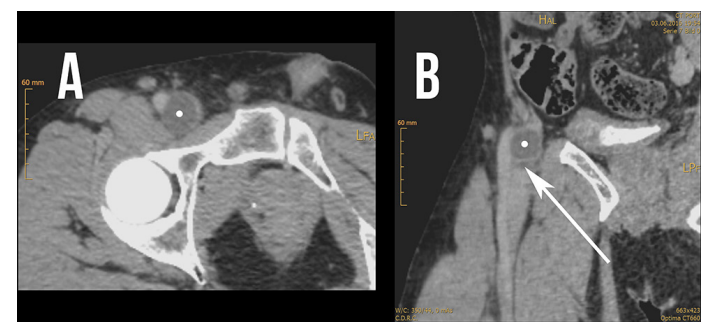

Figure 2 CT venogram axial (A) and coronal (B) reconstruction. Welldefined low attenuation, cystic lesion within the right common femoral vein (circle) with small volume of non-occlusive thrombus just inferior to it $(B$, white arrow) and patent but narrow vessel lumen.

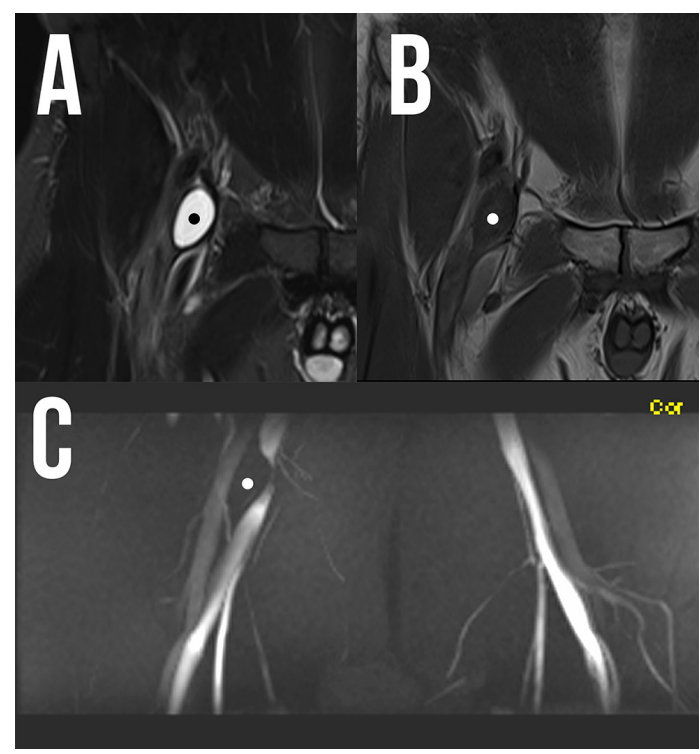

Figure 3 MRI coronal T1 (A) and T2 (B) weighted images with maximum intensity projection of MR venogram (C). Cystic lesion within the right common femoral vein (circles) projects into the vessel lumen, which is narrowed but preserved. Note the normal left common femoral vein $(\mathbf{C})$.

The pattern of disease differs quite significantly between arterial and venous ACD. Anatomically, arterial ACD is most commonly seen in the popliteal segment. Conversely, popliteal vein ACD is extremely rare with only three cases being described in the literature, whereas the iliofemoral veins are the most common site for venous ACD to develop, with 16 previously reported cases of $\mathrm{ACD}$ in the $\mathrm{CFV}$ and 8 previously reported cases of external iliac ACD. ${ }^{2}$

The diagnosis of ACD is challenging for a number of reasons. Apart from reported cases in the popliteal, external iliac and CFV, there have been reports of ACD in the small saphenous and greater saphenous vein, along with a case of ACD in a 'wrist' vein and a deep dermal vein in the ankle. On the contrary, ACD of the artery is more common, where lesions of the popliteal artery are the most frequent. Arterial ACD is reported to be the cause of 1:1200 cases of intermittent claudication. ${ }^{3}$ ACD of the vein is also difficult to diagnose as its clinical presentation is very similar to that of a DVT, with unilateral swelling of the limb.

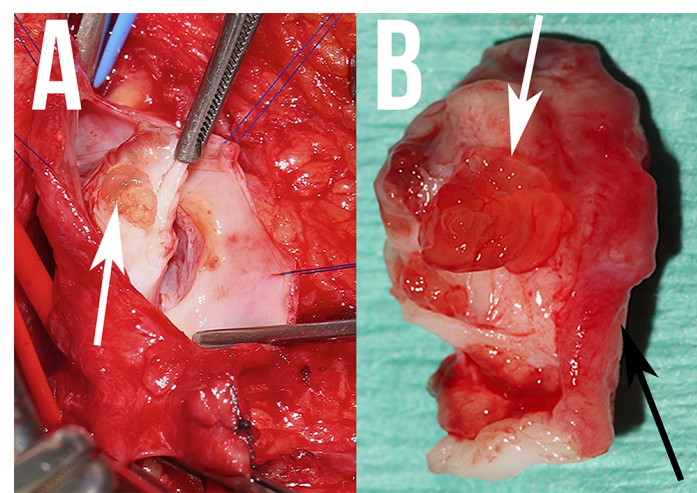

Figure 4 Cystic adventitial disease of the posterior vein wall as seen through an anterior venotomy (A) with gelatinous mucin extruding from the cyst (white arrow). The resected tumour (B) including gelatinous mucin extruding from the cyst (white arrow) and the posterior vein wall attached to the cyst (black arrow). 


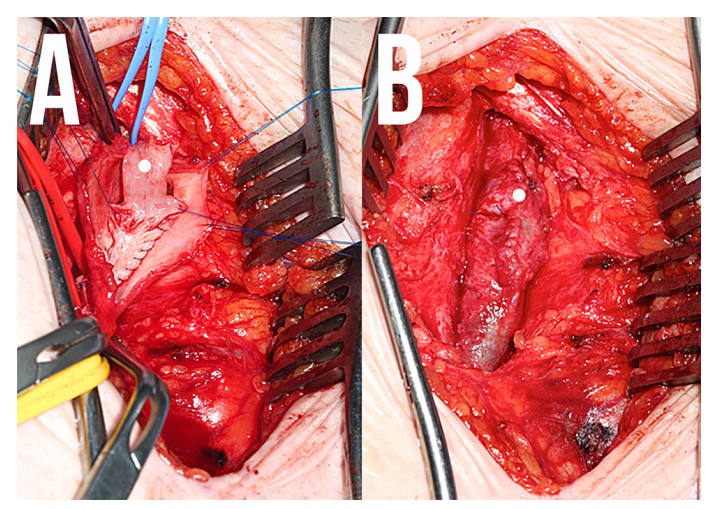

Figure 5 Posterior vein wall defect being repaired $(A)$ with a vein patch (circle) and the completed reconstruction (B) with an additional anterior vein patch (circle).

However, it can present without leg swelling, with the solitary clinical finding of a palpable mass, usually in the groin. ${ }^{4}$

As is usual for unilateral leg swelling, a duplex ultrasound scan is a useful preliminary investigation to assess any underlying structural abnormality of blood vessels. A duplex ultrasound can distinguish between a DVT (appearing as a hyperechoic obstructed vein) and ACD, which is typically seen as a hypoechoic fluid filled cyst structure with posterior acoustic enhancement. ${ }^{5}$ However, as seen in our case both conditions may coexist at presentation making ultrasound assessment very difficult. Furthermore, collateral vessels often form around the cystic mass, which may obscure the venous anatomy. CT and MR venography allow good visualisation of the cyst, the exact anatomical location and the presence and distribution of any collateral vessels. ${ }^{6}$ ACD often demonstrates a classical scalloped or hourglass appearance (figure 3). Disadvantages of CT include the radiation, and the effect of significant limb oedema which may obscure the anatomy. ${ }^{7}$ MR venography can be used for diagnosis, without these disadvantages.

If the leg swelling responds to external compression alone, there may be a case for treating the condition with compression alone or with compression and anticoagulants, as a substantial collateral venous drainage frequently develops just as it does after an iliofemoral DVT. However, in this case, the patient's ongoing employment depended on definitive management.

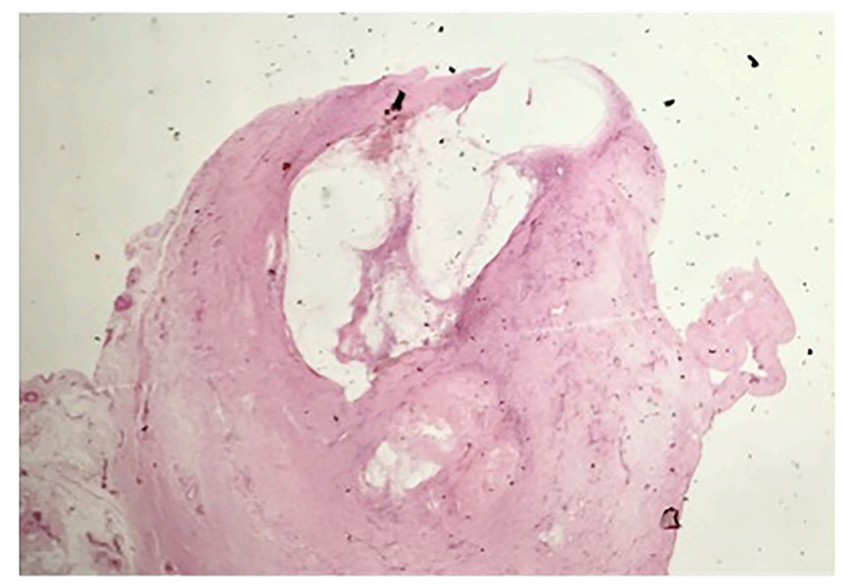

Figure 6 Histological examination of the cystic mass, confirming adventitial cystic disease. Note the presence of cystic degeneration and fibrous connective tissue.
Surgical management involves dissection and excision of the cyst, and when planning the operation it is crucial to know the exact anatomical location and any critical surrounding structures. As there are only a handful of cases published across the world, it is difficult to identify which surgical method gives the best clinical outcomes for the patient. Some authors have used ultrasound-guided percutaneous drainage as a means to resolve the cyst. However, this leaves the mucin and polysaccharide-secreting mesenchymal cells in situ and therefore recurrence of the cyst is highly likely. Others use a reverse saphenous vein interposition graft with complete removal of the cystic lesion and associated segment of vein. ${ }^{8}$ This is more durable than the percutaneous drainage of cysts, although some of the cyst wall may be left behind outside of the vein. ${ }^{2}$ It also seems reasonable, if the original disease is in such a position to allow an adequate local resection, to do this and patch the vein defect(s). There are currently no known endovascular options for the treatment of this condition, although this could change in the future. ${ }^{8}$

In conclusion, $\mathrm{ACD}$ of the venous system is a rare condition, with only a few reported instances in the literature. Its challenge lies in the way its presentation is almost identical to that of a DVT. Treatment of the condition seems promising, with both conservative management and surgical treatments such as excision and vein reconstruction offering satisfactory long-term outcomes.

\section{Learning points}

Adventitial cystic disease (ACD) of the venous system is a rare condition, but an important differential diagnosis to consider in a patient presenting with unilateral leg swelling.

- Diagnosis of ACD clinically is difficult, owing to a similar presentation of a deep vein thrombosis (DVT) and also the frequent coexistence of a DVT.

- Diagnosis relies on clear imaging of the cystic component, using CT or MRI.

- A number of treatment options have been explored; however, complete excision of the cyst is thought to provide the lowest chance of recurrence.

Contributors EH conducted the literature review for the case and made a significant contribution to writing the case report. RB made a significant contribution to the writing and editing of the case report and literature review. CD contributed significantly to collecting, interpreting and producing the radiological images and associated legends of the case. He also contributed to writing and editing the case report. BG initially consulted the patient in clinic and performed the excision of the adventitial cystic disease. He also contributed to the intraoperative findings and images provided in the report. He further contributed to the editing of the case report.

Competing interests None declared.

Patient consent Obtained.

Provenance and peer review Not commissioned; externally peer reviewed

(C) BMJ Publishing Group Ltd (unless otherwise stated in the text of the article) 2017. All rights reserved. No commercial use is permitted unless otherwise expressly granted.

\section{REFERENCES}

1 Vasudevan A, Halak M, Lee $S$, et al. Cystic adventitial disease: a case report and literature review. ANZ J Surg 2005;75:1120-2.

2 Jones DW, Rezayat $C$, Winchester $P$, et al. Adventitial cystic disease of the femoral vein in a 5 -year-old boy mimicking deep venous thrombosis. J Vasc Surg 2012;55:522-4.

3 Tsilimparis N, Hanack U, Yousefi S, et al. Cystic adventitial disease of the popliteal artery: an argument for the developmental theory. J Vasc Surg 2007;45:1249-52.

4 Wu $X$, Lun $Y$, Jiang $H$, et al. Cystic adventitial disease of the common femoral vessels: report of 2 cases and literature review. Vasc Endovascular Surg 2014;48:325-8. 
Rare disease

5 Dix FP, McDonald M, Obomighie J, et al. Cystic adventitial disease of the femoral vein presenting as deep vein thrombosis: a case report and review of the literature. Vasc Surg 2006;44:871-4.

6 Seo JY, Chung DJ, Kim JH. Adventitial cystic disease of the femoral vein: a case report with the CT venography. Korean J Radio/ 2009;10:89-92.
7 Paravastu SC, Regi JM, Turner DR, et al. A contemporary review of cystic adventitial disease. Vasc Endovascular Surg 2012:46:5-14.

8 Mousa AY, Alhalbouni S, Abu-Halimah S, et al. Cystic adventitial disease of the common femoral vein: a case report and review of the literature. Vasc Endovascular Surg 2013;47:569-72.

Copyright 2017 BMJ Publishing Group. All rights reserved. For permission to reuse any of this content visit http://group.bmj.com/group/rights-licensing/permissions.

BMJ Case Report Fellows may re-use this article for personal use and teaching without any further permission.

Become a Fellow of BMJ Case Reports today and you can:

- Submit as many cases as you like

Enjoy fast sympathetic peer review and rapid publication of accepted articles

- Access all the published articles

- Re-use any of the published material for personal use and teaching without further permission

For information on Institutional Fellowships contact consortiasales@bmjgroup.com

Visit casereports.bmj.com for more articles like this and to become a Fellow 